\title{
AN EXAMINATION OF THE REALTIONSHIP BETWEEN COUNTRY OF ORIGIN AND CUSTOMER-BASED BRAND EQUITY: TESTING THE EFFECT OF SOME MODERATORS
}

\author{
Heba Ismail, Damanhour University, Egypt \\ Nadia El-Aref, Alexandria University, Egypt \\ Omneya Yacout, Alexandria University, Egypt
}

\begin{abstract}
This study examines the relationship between the country of origin cue of a brand and the customer-based equity of this brand. In addition, the authors examined the moderating effect of three variables; the personal involvement of the consumers, the consumer's prior experience with the brand and the promotional activities related to the brand. Data were collected from a sample of 250 Egyptian customers. Self-administered questionnaires were distributed and 230 usable questionnaires were returned. The sample included users of five automobiles brands from Korea, France, The United States and Germany. The data were collected from automobile service centers. The authors used moderated regression analysis to test the hypothesized relationships. The findings of this study provide empirical support for the existence of a positive significant association between the country-of-origin of a given brand and the consumer-based equity of this brand ( $\mathrm{R}$ square equals $17.1 \%$ significant at $\mathrm{p}<0.000$ ). In addition, both promotional activity and the perceived risk of mispurchase (a dimension of the personal involvement) show significant moderating effects. $\mathrm{R}$ square after adding these moderators was equal to $35.6 \%$ (for the Chevrolet brand name) and $19.1 \%$ respectively ( $<<0.031$ and $p<0.024$, respectively). Furthermore, the results show a significant main effect of the product perceived importance on the brand equity value (R square equals $20.6 \%$ and $p<0.003$ ). The results are consistent with the suggestions in the literature assuming that consumers rely on the country-of-origin information particularly in the case of unfamiliarity with the product and/or the brand. Unlike many other studies, the consumer's prior experience with the product did not show a significant moderating effect for all of the brands selected. This study is considered one of very few studies that examined the relationship between brand equity and country-of-origin in the Middle East. It also provides insights to practitioners working in the Middle East as to the importance of promotional activities emphasizing country-of-origin and negative consequences of mispurchase in their efforts to market high involvement products.
\end{abstract}

References available upon request 